\title{
The sternocleidomastoid muscle flap for the prevention of Frey syndrome and cosmetic deformity following parotidectomy: A systematic review and meta-analysis
}

\author{
DONG YAN LIU ${ }^{1}$, XIAO JIAO TIAN ${ }^{2}$, CHENG LI $^{3}$, SHAO SHAN SUN ${ }^{4}$, YING HUI XIONG ${ }^{1}$ and XIAN-TAO ZENG ${ }^{1}$ \\ Departments of ${ }^{1}$ Stomatology and ${ }^{2}$ Neurosurgery, Taihe Hospital, Hubei University of Medicine, \\ Shiyan 442000; ${ }^{3}$ Department of Oral and Maxillofacial Surgery, School and Hospital of Stomatology, \\ Wuhan University, Wuhan 430079; ${ }^{4}$ Department of Stomatology, People's Hospital of Beijing Daxing District, \\ Capital Medical University, Beijing 102600, P.R. China
}

Received October 15, 2012; Accepted January 28, 2013

DOI: 10.3892/ol.2013.1179

\begin{abstract}
Approximately 34-86\% of neoplasms of the salivary glands are located in the parotid gland and parotidectomy is the first-line treatment for parotid gland tumors. Frey syndrome and cosmetic deformity are common complications experienced by patients following parotidectomy and the sternocleidomastoid muscle flap (SCMF) is used to prevent them. Numerous studies have been performed to examine the effectiveness of the SCMF for the prevention of cosmetic deformity and Frey syndrome, however, they provide contradictory results and possess small sample sizes with consequently low statistical power. In order to evaluate the effectiveness of the SCMF for the prevention of Frey syndrome and cosmetic deformity following parotidectomy, we performed a systematic review and meta-analysis based on published randomized controlled trials (RCTs), which were identified using PubMed and CNKI databases, and references of studies up to August 2012 were included. Using these criteria, we yielded 11 RCTs. Following an independent assessment of the methodological quality of these studies and the extraction of data, a systematic review and meta-analysis was conducted. The results of the meta-analysis demonstrated that there was a significant trend towards a lower risk of objective incidence [67\%; risk ratio (RR), $0.33 ; 95 \%$ confidence interval $(\mathrm{CI}), 0.16-0.67 ; \mathrm{P}<0.01]$ and subjective incidence (66\%; RR, 0.34; 95\% CI, 0.16-0.75; P=0.01) of Frey syndrome in the SCMF group. The sensitivity analysis also indicated that this result was significant. Due to the consider-
\end{abstract}

Correspondence to: Dr Xian-Tao Zeng, Department of Stomatology, Taihe Hospital, Hubei University of Medicine, 32 South Renmin Road, Shiyan 442000, P.R. China

E-mail: zengxiantao1128@163.com

Key words: sternocleidomastoid muscle flap, Frey syndrome, gustatory sweating syndrome, cosmetic deformity, parotidectomy, systematic review able variation between the included studies, a meta-analysis was not applicable to assess cosmetic deformity. Two RCTs demonstrated that the difference between the SCMF and no SCMF group was not statistically significant, while the other seven RCTs detected a statistically significant difference between the two groups. Publication bias was detected. In conclusion, based on currently available evidence, the use of the SCMF is benefical for the prevention of Frey syndrome, however, whether it is also benefical for cosmetic deformity remains inconclusive.

\section{Introduction}

Approximately $34-86 \%$ of neoplasms of the salivary glands are located in the parotid gland $(1,2)$. Parotidectomy is the first-line treatment for parotid gland tumors $(3,4)$. However, complications experienced following surgery significantly reduce patients' quality of life (5). The most common complications are cosmetic deformity and Frey syndrome.

Owing to all or part of the parotid gland being removed, facial depression is observed in almost $100 \%$ of patients who have undergone parotidectomy. Frey syndrome was first described by Łucja Frey in 1923 (6), with an incidence of between 11 and $95 \%(7,8)$. It is characterized by flushing or sweating on one side of the forehead, face, scalp and neck occurring soon following the ingestion of food, in response to salivatory stimulation (9).

The use of autogenous tissue interposition for the prevention of Frey syndrome and cosmetic deformity during parotidectomy are considered as simple, safe and effective approaches by clinicians. The sternocleidomastoid myocutaneous flap (SCMF) is one of the most commonly used autogenous tissues (10). Numerous studies have been performed to examine the effectiveness of the SCMF for the prevention of cosmetic deformity and Frey syndrome, however, they provide contradictory results and have small samples sizes with consequently low statistical power.

In 2010, Sanabria et al (10) conducted a meta-analysis investigating the effectiveness of the SCMF for the prevention of cosmetic deformity and Frey syndrome. The study included 
two randomized controlled trials (RCTs) $(11,12)$. At the time of writing this manuscript, eleven RCTs have been published. A comprehensive systematic review and meta-analysis is therefore required to provide an updated review of the effectiveness of the SCMF for the prevention of cosmetic deformity and Frey syndrome.

\section{Materials and methods}

Report terms. We attempted to follow the proposed PRISMA (Preferred Reporting Items for Systematic Reviews and MetaAnalyses) guidelines (13) to report the present systematic review and meta-analysis.

Literature search. We conducted a PubMed and CNKI database search in August 2012 for relevant studies that examined the effectiveness of the SCMF for the prevention of cosmetic deformity and/or Frey syndrome. The following search terms were used: i) Frey's syndrome, Frey syndrome, gustatory sweating, auriculotemporal syndrome, cosmetic deformity, facial depression and cosmetic disfigurement; ii) sternocleidomastoid. These two search terms were combined using the Boolean operator 'and'. No restrictions were imposed. In addition, we examined the reference lists of the retrieved RCTs and recently published reviews.

Study selection. We conducted an initial screening of titles or abstracts. Following this, we performed a second screening based on full-text review. Studies were considered eligible if they met the following criteria: i) the study design was an RCT; ii) the study included patients with benign or malignant parotid tumors who underwent partial or total parotidectomy with facial nerve preservation, and without a history of previous surgical procedures in the parotid area or previous radiotherapy; iii) interventions included the SCMF, and the control group constituted no SCMF or other prophylactic measures; iv) the main outcome was incidence of cosmetic deformity and/or Frey syndrome, determined with subjective or objective measures; v) data of each outcome were reported or obtained by contacting the corresponding author of the study.

Data extraction. Two authors (XJ Tian and YH Xiong) independently extracted the following data for each eligible study: first author's last name, year of publication, site of origin, sample size, characteristics of the SCMF and control groups, outcome evaluation methods, length of follow-up, incidence of cosmetic deformity and Frey syndrome. Any disagreements were resolved by consulting a third author (XT Zeng).

Assessment of methodological quality. The methodological quality of each study was assessed using the Cochrane collaboration's tool for assessing risk of bias (14), which contains the following seven criteria: i) details of the randomization method; ii) allocation concealment; iii) blinding of participants and personnel; iv) blinding of outcome assessment; v) incomplete outcome data; vi) selective outcome reporting and vii) other sources of bias. Each study was assessed by two authors (DY Liu and XJ Tian) independently and any disagreements were resolved by consulting a third author (XT Zeng).

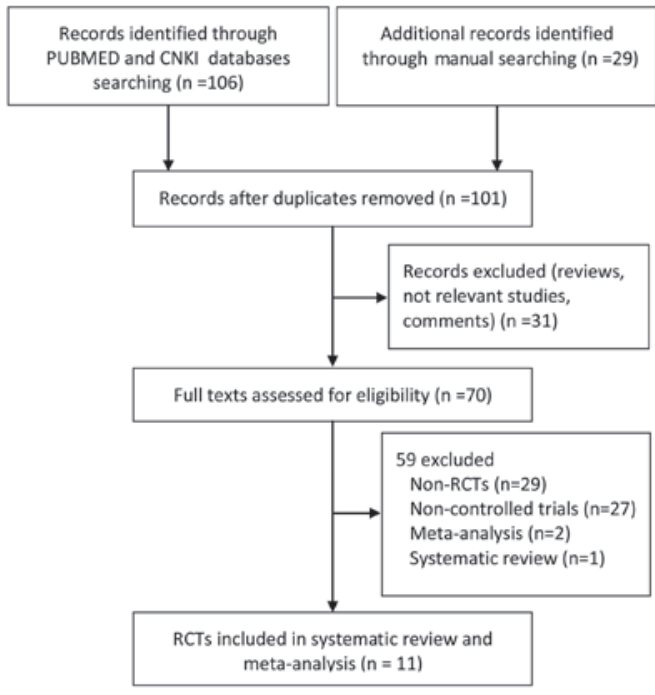

Figure 1. Summary of the study selection process. RCTs, randomized controlled trials.

Data synthesis and analysis. We calculated risk ratios (RRs) and $95 \%$ confidence intervals (CIs) for all studies with sufficient data. Heterogeneity was examined using the Cochrane Q test and quantified with the $\mathrm{I}^{2}$ statistic (15). The value of the $\mathrm{I}^{2}$ statistic was used to select the appropriate pooling method: if the $\mathrm{I}^{2}$ value was $<50 \%$, the fixed-effects meta-analysis was applied; if the $\mathrm{I}^{2}$ value was $\geq 50 \%$, the random-effects metaanalysis was used.

In the presence of heterogeneity, we performed sensitivity analyses by removal of each study in turn in order to examine the robustness of the main results. Potential publication bias was investigated by visual assessment using a funnel plot and further examined using a combination of the Egger regression test (16) and the 'trim and fill' method (17).

Statistical analyses were conducted with Comprehensive Meta-Analysis software, version 2.2 (Biostat, Englewood, New Jersey, USA) (18). For all comparisons, except those for heterogeneity, $\mathrm{P}<0.05$ was considered to indicate a statistically significant result. All tests were two-sided.

\section{Results}

Search results. An initial search yielded 135 potentially relevant studies and 11 RCTs $(11,12,19-27)$ were selected for the purpose of our analysis. Fig. 1 depicts a flowchart showing the study selection process and their characteristics are listed in Table I.

Methodological quality. Table II shows the quality of RCTs according to the Cochrane collaboration's tool. It refers to randomization only, lacking information with regard to allocation concealment and blinding; however, no incomplete outcome data, no selective outcome reporting and other sources of bias were observed. Therefore, there was a moderate risk of bias.

Frey syndrome. Nine RCTs $(11,12,19-22,24,26,27)$ reported the incidence of objective Frey syndrome by performing the starch-iodine test. A significant heterogeneity was observed 


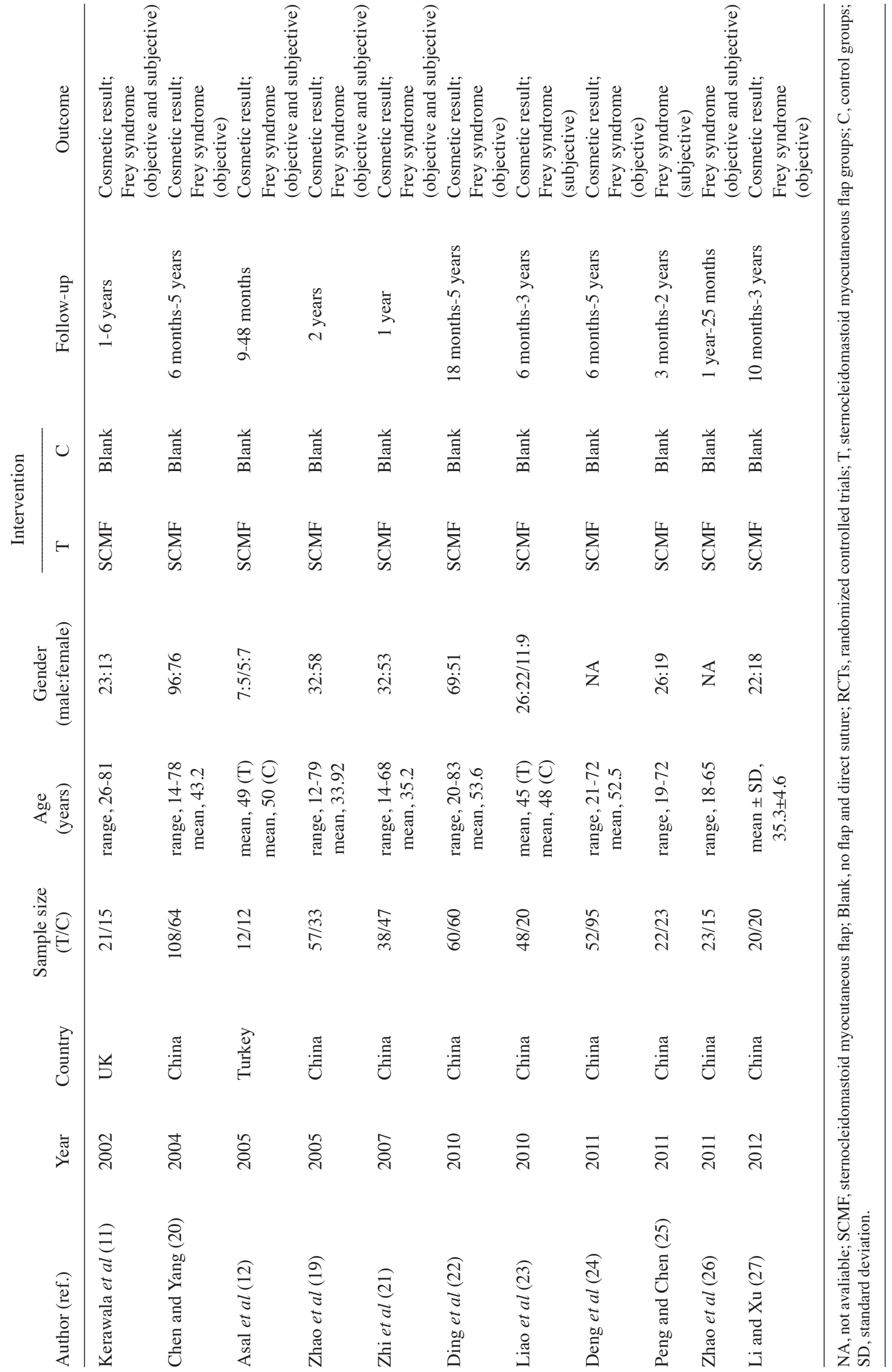


Table II. Quality of included RCTs according to the Cochrane collaboration's tool.

\begin{tabular}{|c|c|c|c|c|c|c|c|c|}
\hline Author (ref.) & Year & $\begin{array}{c}\text { Randomization } \\
\text { method }\end{array}$ & $\begin{array}{c}\text { Allocation } \\
\text { concealment }\end{array}$ & $\begin{array}{c}\text { Incomplete } \\
\text { outcome } \\
\text { data }\end{array}$ & $\begin{array}{c}\text { Blinding of } \\
\text { participants } \\
\text { and personnel }\end{array}$ & $\begin{array}{l}\text { Blinding of } \\
\text { outcome } \\
\text { assessment }\end{array}$ & $\begin{array}{l}\text { Selective } \\
\text { outcome } \\
\text { reporting }\end{array}$ & $\begin{array}{c}\text { Other } \\
\text { sources } \\
\text { of bias }\end{array}$ \\
\hline Kerawala et al (11) & 2002 & Low & Unclear & Low & Low & Low & Low & Low \\
\hline Chen and Yang (20) & 2004 & Unclear & Unclear & Unclear & Low & Low & Low & Low \\
\hline Asal et al (12) & 2005 & Unclear & Unclear & Low & Low & Low & Low & Low \\
\hline Zhao et al (19) & 2005 & Unclear & Unclear & Unclear & Unclear & Low & Low & Low \\
\hline Zhi et al (21) & 2007 & Unclear & Unclear & Unclear & Low & Low & Low & Low \\
\hline Ding et al (22) & 2010 & Unclear & Unclear & Unclear & Low & Low & Low & Low \\
\hline Liao et al (23) & 2010 & High & Unclear & Unclear & Unclear & Low & Low & Low \\
\hline Deng et al (24) & 2011 & Unclear & Unclear & Unclear & Low & Low & Low & Low \\
\hline Peng and Chen (25) & 2011 & Unclear & Unclear & Unclear & Low & Low & Low & Low \\
\hline Zhao et al (26) & 2011 & Unclear & Unclear & Unclear & Low & Low & Low & Low \\
\hline $\mathrm{Li}$ and $\mathrm{Xu}(27)$ & 2012 & Unclear & Unclear & Unclear & Unclear & Low & Low & Low \\
\hline
\end{tabular}

RCTs, randomized controlled trials.

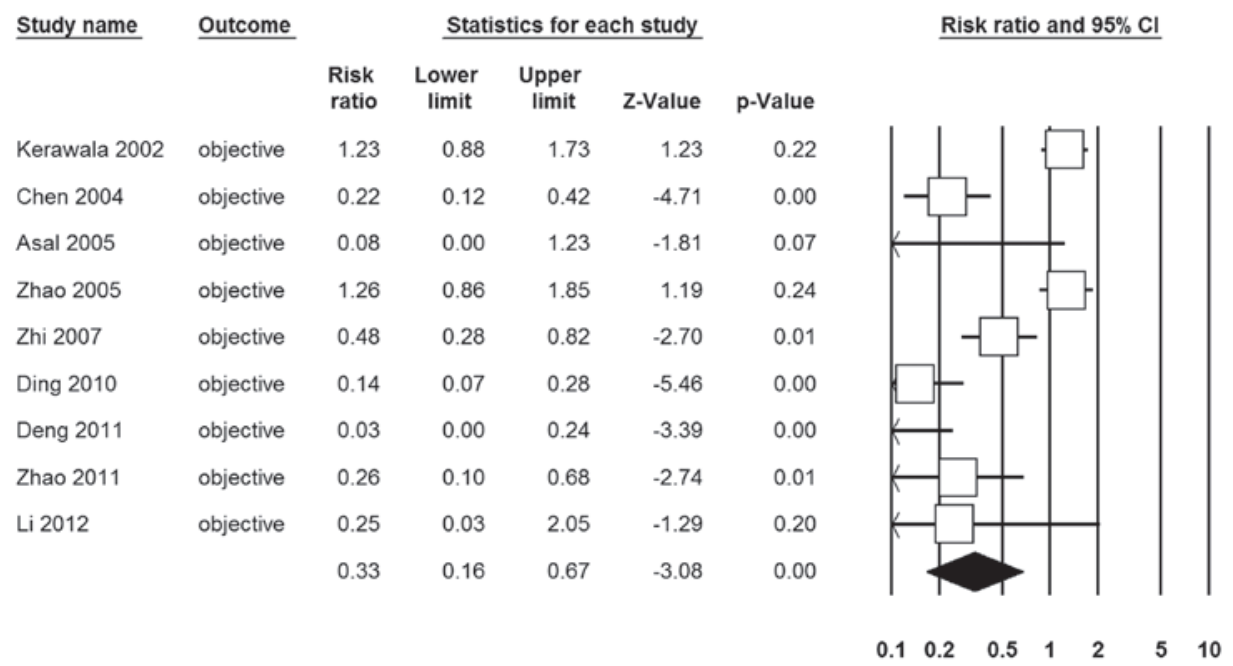

Figure 2. Forest plot of the risk ratios and $95 \% \mathrm{CI}$ of the incidence of objective Frey syndrome. CI, confidence interval.

\begin{tabular}{|c|c|c|c|c|c|c|c|}
\hline \multirow[t]{2}{*}{$\underline{\text { Study name }}$} & \multirow[t]{2}{*}{ Outcome } & \multirow[b]{2}{*}{ Point } & \multicolumn{3}{|c|}{ Statistics with study removed } & & \multirow{2}{*}{$\begin{array}{l}\text { Risk ratio }(95 \% \mathrm{Cl}) \\
\text { with study removed }\end{array}$} \\
\hline & & & $\begin{array}{c}\text { Lower } \\
\text { limit }\end{array}$ & $\begin{array}{l}\text { Upper } \\
\text { limit }\end{array}$ & Z-Value & p-Value & \\
\hline Kerawala 2002 & objective & 0.26 & 0.12 & 0.58 & -3.30 & 0.00 & \\
\hline Chen 2004 & objective & 0.36 & 0.17 & 0.75 & -2.74 & 0.01 & \\
\hline Asal 2005 & objective & 0.36 & 0.17 & 0.73 & -2.83 & 0.00 & \\
\hline Zhao 2005 & objective & 0.26 & 0.11 & 0.58 & -3.26 & 0.00 & \\
\hline Zhi 2007 & objective & 0.30 & 0.13 & 0.69 & -2.85 & 0.00 & \\
\hline Ding 2010 & objective & 0.40 & 0.20 & 0.78 & -2.66 & 0.01 & \\
\hline Deng 2011 & objective & 0.40 & 0.20 & 0.80 & -2.61 & 0.01 & \\
\hline Zhao 2011 & objective & 0.34 & 0.16 & 0.73 & -2.79 & 0.01 & \\
\hline Li 2012 & objective & 0.34 & 0.16 & 0.70 & -2.91 & 0.00 & \\
\hline & & 0.33 & 0.16 & 0.67 & -3.08 & 0.00 & \\
\hline
\end{tabular}

Figure 3. Forest plot of the risk ratios and 95\% CI of the incidence of objective Frey syndrome following sensitivity analysis performed by removing each study consecutively. CI, confidence interval. 


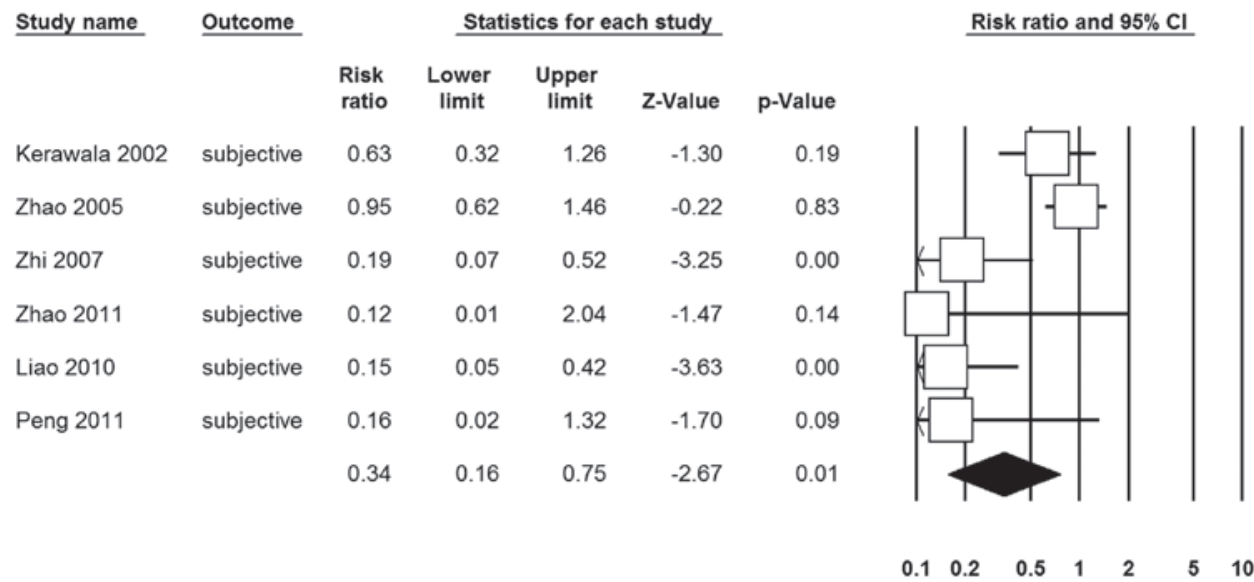

Figure 4. Forest plot of the risk ratios and $95 \%$ CI of the incidence of subjective Frey syndrome. CI, confidence interval.

\begin{tabular}{|c|c|c|c|c|c|c|c|}
\hline \multirow[t]{2}{*}{ Study name } & \multirow[t]{2}{*}{ Outcome } & \multirow[b]{2}{*}{ Point } & \multicolumn{3}{|c|}{ Statistics with study removed } & \multirow[b]{2}{*}{ p-Value } & \multirow{2}{*}{$\begin{array}{l}\text { Risk ratio }(95 \% \mathrm{Cl}) \\
\text { with study removed }\end{array}$} \\
\hline & & & $\begin{array}{c}\text { Lower } \\
\text { limit }\end{array}$ & $\begin{array}{c}\text { Upper } \\
\text { limit }\end{array}$ & z-Value & & \\
\hline Kerawala 2002 & subjective & 0.26 & 0.09 & 0.80 & -2.35 & 0.02 & \\
\hline Zhao 2005 & subjective & 0.26 & 0.12 & 0.55 & -3.50 & 0.00 & \\
\hline Zhi 2007 & subjective & 0.40 & 0.17 & 0.92 & -2.15 & 0.03 & \\
\hline Zhao 2011 & subjective & 0.37 & 0.16 & 0.83 & -2.42 & 0.02 & \\
\hline Liao 2010 & subjective & 0.44 & 0.20 & 0.94 & -2.12 & 0.03 & \\
\hline \multirow[t]{2}{*}{ Peng 2011} & subjective & 0.37 & 0.16 & 0.85 & -2.35 & 0.02 & \\
\hline & & 0.34 & 0.16 & 0.75 & -2.67 & 0.01 & \\
\hline
\end{tabular}

Figure 5. Forest plot of the risk ratios and 95\% CI of the incidence of subjective Frey syndrome following sensitivity analysis performed by removing each study consecutively. CI, confidence interval.

$\left(\mathrm{I}^{2}=88.79 \%, \mathrm{P}<0.10\right)$, therefore we used a random-effects model. The meta-analysis demonstrated that the SCMF markedly decreased the risk of incidence of Frey syndrome (67\%; RR, 0.33; 95\% CI, 0.16-0.67; P<0.01; Fig. 2). Sensitivity analysis was performed by sequential removal of each study and the significance of pooled RR was not influenced by omitting any single study, suggesting that the result of this meta-analysis was stable (Fig. 3).

Seven RCTs $(11,12,19,21,23,26,28)$ reported the subjective incidence of Frey syndrome. A significant heterogeneity $\left(\mathrm{I}^{2}=74.24 \%, \mathrm{P}<0.10\right)$ was observed, therefore, the randomeffects model was used. The result also demonstrated that there was a significant correlation towards a lower risk of incidence in the SCMF group (66\%; RR, 0.34; 95\% CI, 0.16-0.75; $\mathrm{P}=0.01$; Fig. 4). The sensitivity analysis also indicated this result was significant (Fig. 5).

Cosmetic results. Nine RCTs $(11,12,19-24,27)$ observed cosmetic deformity. Due to the considerable variation among included studies, meta-analysis was not applicable. Two RCTs $(11,12)$ demonstrated that the differences between the SCMF and no SCMF group were not statistically significant, while the other seven RCTs demonstrated that the cosmetic appearance was statistically significant for the SCMF group compared with the no SCMF group. Table III indicates a qualitative analysis of the evidence.

Publication bias. Fig. 6 demonstrates that the funnel plot was asymmetrical (based on the evaluation of objective Frey syndrome), which indicated that publication bias existed (white circles). The Egger linear regression also detected moderate publication bias among studies (Egger, $\mathrm{P}=0.023$ ). As evidence of bias may be due to inadequate statistical power, we used a non-parametric method of 'trim and fill' to estimate two possible missing studies (black spots in Fig. 6), the estimated RR including the 'missing' studies was not substantially different from our estimate with an adjustment for the missing studies (RR, 0.43; 95\% CI, 0.22-0.88).

\section{Discussion}

In 1927, Andre Thomas described the pathophysiology of Frey syndrome as the aberrant regeneration of sectioned parasympathetic fibers, which regrow to innervate the vessels and sweat glands of the skin overlying the parotid (29). Accepting this pathophysiology and mechanism, oral and maxillofacial 
Table III. Cosmetic result of included RCTs.

\begin{tabular}{|c|c|c|c|c|}
\hline Author (ref.) & Year & Assessment method & Result (C/T) & Conclusion \\
\hline Kerawala et al (11) & 2002 & VAS & $\begin{array}{l}\text { Subjective: } 1.5 \pm 1.6 / 2.6 \pm 2.1, \mathrm{P}=0.13 \text {; } \\
\text { objective: } 2.8 \pm 1.3 / 3.5 \pm 1.3, \mathrm{P}=0.12\end{array}$ & Insignificant difference \\
\hline Chen and Yang (20) & 2004 & Doctor observed & Marked/inconspicuous, $\mathrm{P}<0.01$ & Significant difference \\
\hline Asal et al (12) & 2005 & $\begin{array}{l}\text { Questionnaire } \\
\text { and doctor } \\
\text { observed }\end{array}$ & $\begin{array}{l}\text { Subjective: all patients were } \\
\text { pleased with the cosmetic result; } \\
\text { objective: the facial contours of } 7 / 6 \\
\text { patients were not unsatisfied } \\
\text { to the otolaryngologist }\end{array}$ & Insignificant difference \\
\hline Zhao et al (19) & 2005 & Questionnaire & $22 / 4$ patients felt unsatisfied, $\mathrm{P}<0.05$ & Significant difference \\
\hline Zhi et al (21) & 2007 & Questionnaire & $\begin{array}{l}26 / 4 \text { patients experienced } \\
\text { earlobe depression, } \mathrm{P}<0.05\end{array}$ & Significant difference \\
\hline Ding et al (22) & 2010 & $\begin{array}{l}\text { Doctor and } \\
\text { patient observed }\end{array}$ & $\begin{array}{l}60 / 2 \text { patients experienced } \\
\text { facial depression, } \mathrm{P}=0.0014\end{array}$ & Significant difference \\
\hline Liao et al (23) & 2010 & Doctor observed & $\begin{array}{l}18 / 8 \text { patients experienced } \\
\text { facial depression, } \mathrm{P}<0.01\end{array}$ & Significant difference \\
\hline Deng et al (24) & 2011 & $\begin{array}{l}\text { Doctor observed } \\
\text { and examined }\end{array}$ & $\begin{array}{l}79 / 6 \text { patients experienced } \\
\text { facial depression, } \mathrm{P}<0.01\end{array}$ & Significant difference \\
\hline $\mathrm{Li}$ and $\mathrm{Xu}(27)$ & 2012 & $\begin{array}{l}\text { Reported by } \\
\text { patient }\end{array}$ & $\begin{array}{l}6 / 0 \text { patients felt } \\
\text { unsatisfied, } \mathrm{P}<0.05\end{array}$ & Significant difference \\
\hline
\end{tabular}

VAS, 10-cm visual analog scale; RCTs, randomized controlled trials; T, sternocleidomastoid myocutaneous flap groups; C, control groups.

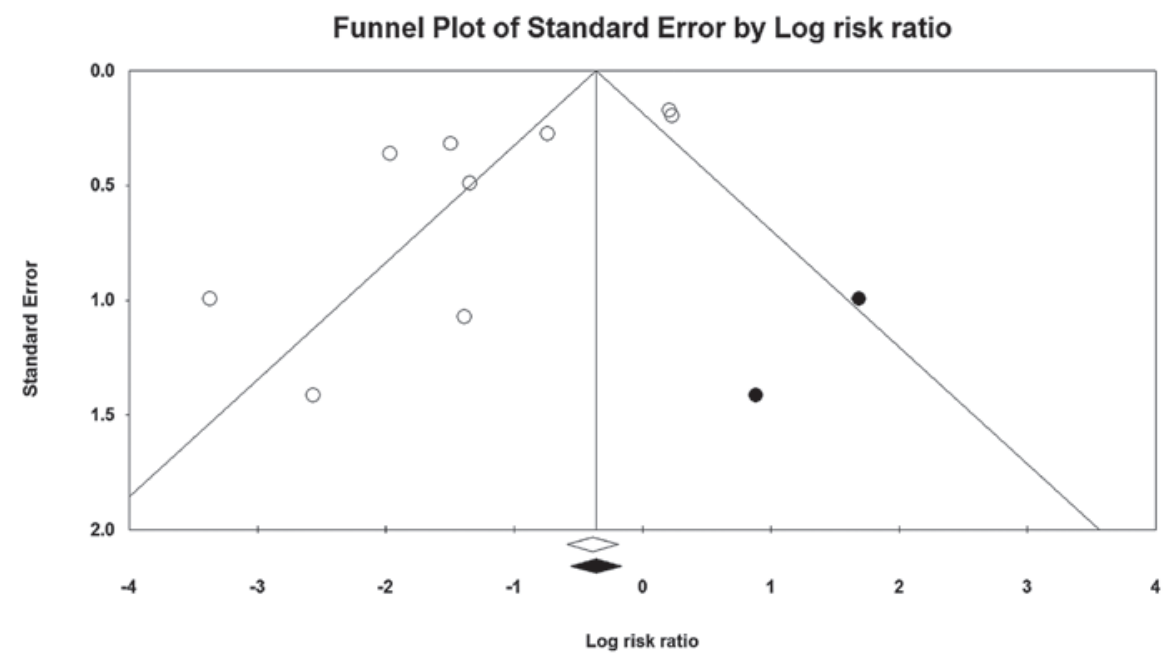

Figure 6. Filled funnel plot with pseudo-95\% CIs for the evaluation of objective Frey syndrome. A circle represents a study, while a black spot represents an unpublished study that is required to negate the results of the meta-analysis. CI, confidence interval.

surgeons proposed to interpose any tissue between the parotid bed and the skin, including the temporoparietal fascia rotational flap (30), the superficial muscular aponeurotic system (SMAS) (31), the SCMF and AlloDerm (32), with the aim of inhibiting aberrant innervation in order to prevent Frey syndrome.

Compared with other autogenous tissue flaps, the SCMF has several advantages: i) it is easy to rotate into the parotid region without another incision; ii) it is long enough to cover all the branches of the facial nerve; iii) it decreases the depression of the surgical area following parotid gland resec- tion; iv) there is a low risk of necrosis of the flap due to its vascularization and $v$ ) there is a low risk of complications, primarily, spinal accessory nerve injury (10). Compared with AlloDerm, the major advantage of the SCMF is that it is more cost-effective.

The first RCT of the SCMF was published by Kerawala et al (11) in 2002. Following that, a number of additional RCTs have been published. However, the results are inconsistent. In 2010, Sanabria et al (10) performed a meta-analysis of the SCMF for the prevention of Frey syndrome, including two RCTs and nine non-RCTs. The authors concluded that the 
result of their meta-analysis was inconclusive with regard to the use of the SCMF as an intervention for the prevention of Frey syndrome following parotid surgery. It is widely considered that a non-RCT design introduces a higher degree of bias compared with a RCT design. Therefore, we conducted a meta-analysis which only included RCTs in order to obtain a more accurate result. The meta-analysis demonstrated that the SCMF is capable of clearly decreasing the incidence of objective and subjective Frey syndrome. The sensitivity analysis indicated that the result was robust.

Some studies have indicated that the SCMF evidently improves cosmetic appearance compared with no flap and some studies have indicated that this function was limited. Due to the considerable variation of the assessment methods used among the included studies, a meta-analysis was not performed. Our systematic review did not obtain a conclusive result.

However, there are some limitations with regard to our systematic review and meta-analysis that should be stated. Firstly, the sample size of the studies contributing a significant amount of data to this meta-analysis was small, therefore, we were not able to adequately assess the effects of prevention. Secondly, the methodological quality of the included RCTs demonstrated a moderate risk of bias, and a lack of information with regard to randomization, allocation concealment and blinding (some RCTs) may have introduced bias. Thirdly, a significant heterogeneity between RCTs existed, although sensitivity analysis revealed that it did not exert a significant influence. However, its potential influence should be considered. Fourthly, publication bias was detected, the 'file-drawer' effect may exist and our 'trim and fill' analysis also estimated two possible missing studies, which indicated that studies that reported negative results may be more likely to remain unpublished. Lastly, a meta-analysis of the cosmetic result was not conducted, so we are not able to obtain a quantitative result for this outcome.

For future studies, we suggest that the same measurment tools are applied, including the $10-\mathrm{cm}$ visual analog scale (11) and blinding to the evalution of the cosmetic result. We also suggest to perform RCTs to compare the effectiveness of the SCMF and AlloDerm, as AlloDerm is presently widely used for the prevention of Frey syndrome (32). We recommend the use of the starch-iodine test and blinding in studies with regard to Frey syndrome in future studies. As the method of parotidectomy (4) and prognosis (33) are influenced by benign and malignant tumors, diagnosis of parotid gland lesions prior to parotidectomy is important. A well accepted, safe, reliable, minimally invasive and cost-effective method, including fine needle aspiration cytology (34) is recommended.

In conclusion, based on currently available evidence, the use of the SCMF is beneficial for the prevention of Frey syndrome, however, whether it is additionally benefical for cosmetic deformity remains inconclusive.

\section{Acknowledgements}

This study was supported by the Foundation of Education and Science Planning Project of Hubei Province (No. 2012A050), the Nature Science Foundation of Hubei Province (2012FFB03902) and the Intramural Research Program of the Hubei University of Medicine (No. 2011CZX01), without commercial or not-for-profit sectors.

\section{References}

1. Vuhahula EA: Salivary gland tumors in Uganda: clinical pathological study. Afr Health Sci 4: 15-23, 2004.

2. Pinkston JA and Cole P: Incidence rates of salivary gland tumors: results from a population-based study. Otolaryngol Head Neck Surg 120: 834-840, 1999.

3. Clayman MA, Clayman SM and Seagle MB: A review of the surgical and medical treatment of Frey syndrome. Ann Plast Surg 57: 581-584, 2006.

4. Ali NS, Nawaz A, Rajput S and Ikram M: Parotidectomy: a review of 112 patients treated at a teaching hospital in Pakistan. Asian Pac J Cancer Prev 11: 1111-1113, 2010.

5. Nitzan D, Kronenberg J, Horowitz Z, et al: Quality of life following parotidectomy for malignant and benign disease. Plast Reconstr Surg 114: 1060-1067, 2004.

6. Dulguerov P, Marchal F and Gysin C: Frey syndrome before Frey: the correct history. Laryngoscope 109: 1471-1473, 1999.

7. Koch M, Zenk J and Iro H: Long-term results of morbidity after parotid gland surgery in benign disease. Laryngoscope 120: 724-730, 2010.

8. de Bree R, van der Waal I and Leemans CR: Management of Frey syndrome. Head Neck 29: 773-778, 2007.

9. Dulguerov P, Quinodoz D, Vaezi A, Cosendai G, Piletta P and Lehmann W: New objective and quantitative tests for gustatory sweating. Acta Otolaryngol 119: 599-603, 1999.

10. Sanabria A, Kowalski LP, Bradley PJ, et al: Sternocleidomastoid muscle flap in preventing Frey's syndrome after parotidectomy: a systematic review. Head Neck 34: 589-598, 2012.

11. Kerawala CJ, McAloney N and Stassen LF: Prospective randomised trial of the benefits of a sternocleidomastoid flap after superficial parotidectomy. Br J Oral Maxillofac Surg 40: 468-472, 2002

12. Asal K, Köybaşioğlu A, Inal E, et al: Sternocleidomastoid muscle flap reconstruction during parotidectomy to prevent Frey's syndrome and facial contour deformity. Ear Nose Throat J 84: $173-176,2005$.

13. Liberati A, Altman DG, Tetzlaff J, et al: The PRISMA statement for reporting systematic reviews and meta-analyses of studies that evaluate health care interventions: explanation and elaboration. J Clin Epidemiol 62: e1-e34, 2009.

14. Zeng XT, Bao CP, Cao SY and Liu JY: The third part in metaanalysis series: Tools for assessing the quality of randomized controlled trials. Chin J Evid Based Cardiovasc Med 4: 183-185, 2012 (In Chinese).

15. Higgins JP and Thompson SG: Quantifying heterogeneity in a meta-analysis. Stat Med 21: 1539-1558, 2002.

16. Egger M, Davey Smith G, Schneider M and Minder C: Bias in meta-analysis detected by a simple, graphical test. BMJ 315: 629-634, 1997.

17. Duval S and Tweedie R: Trim and fill: A simple funnel-plotbased method of testing and adjusting for publication bias in meta-analysis. Biometrics 56: 455-463, 2000.

18. Borenstein M, Hedges L and Rothstein H: Comprehensive Meta-analysis. Biostat, Englewood, New Jersey: 2005 (computer software).

19. Zhao HW, Li LJ, Han B, Liu H and Pan J: A retrospective study on the complications after modified parotidectomy in benign tumors of parotid gland. Hua Xi Kou Qiang Yi Xue Za Zhi 23: 53-56, 2005 (In Chinese).

20. Chen R and Yang K: Clinical observation of sternocleidomastoid muscle flap to repair tissue defect and in preventing Frey syndrome after parotidectomy. Chongqing Yi Yao 33: 94-95, 2004 (In Chinese).

21. Zhi KQ, Wen YM and Li LJ: Prevention and treatment of complications following benign parotid neoplasms dissection. Xi'an Jiao Tong Da Xue Xue Bao. Yi Xue Ban 28: 116-117, 2007 (In Chinese).

22. Ding YF, Zhou PG, Gu YC and Chen Y: Applicatian of sternocleidomastoid muscle flap in benign parotidectomies. J Dental Preven Treat 18: 88-90, 2010 (In Chinese).

23. Liao SK, Li JC, Zhang K, Xu JC, Xu T and Chen YF: Clinical study of 48 cases of sternocleidomastoid muscle flap in parotidectomy. Shi Yong Kou Qiang Yi Xue Za Zhi 3: 106-108, 2010 (In Chinese). 
24. Deng YQ, Zheng CS and Zhu YM: Application of sternocleidomastoid muscle flap and parotid fascia flap in operation on parotid benign tumor. J Oral Sci Res 27: 893-895, 2011.

25. Peng YF and Chen YD: Clinical analysis of 45 cases of parotid gland tumor. Zhong Wai Jian Kang Wen Zhai 8: 241, 2011 (In Chinese).

26. Zhao J, Yu HQ and Liu AG: Comparative study of using heterogeneous acellular dermal matrix and reconstruction of parotid masseter faseial in prevention of Frey's syndrome after parotidectomy. Stomatology 31: 356-359, 2011 (In Chinese).

27. Li MD and Xu JM: Clinical study of veiled incision and sternocleidomastoid flap in the operation of parotid gland tumor. Zhong Wai Yi Liao 31: 44-46, 2012 (In Chinese).

28. Li C, Fan JC, Li B, et al: Meta-analysis of surgical techniques for preventing Frey syndrome and a concave facial deformity after parotidectomy. Zhonghua Er Bi Yan Hou Tou Jing Wai Ke Za Zhi 46: 580-585, 2011 (In Chinese).

29. Glaister DH, Hearnshaw JR, Heffron PF, Peck AW and Patey DH: The mechanism of post-parotidectomy gustatory sweating (the auriculo-temporal syndrome). Br Med J 2: 942-946, 1958.
30. Rubinstein RY, Rosen A and Leeman D: Frey syndrome: treatment with temporoparietal fascia flap interposition. Arch Otolaryngol Head Neck Surg 125: 808-811, 1999.

31. Moulton-Barrett R, Allison G and Rappaport I: Variation's in the use of SMAS (superficial musculoaponeurotic system) to prevent Frey's syndrome after parotidectomy. Int Surg 81: 174-176, 1996.

32. Zeng XT, Tang XJ, Wang XJ, et al: AlloDerm implants for prevention of Frey syndrome after parotidectomy: a systematic review and meta-analysis. Mol Med Rep 5: 974-980, 2012.

33. Oliveira LR, Soave DF, Oliveira-Costa JP, Zorgetto VA and Ribeiro-Silva A: Prognostic factors in patients with malignant salivary gland neoplasms in a Brazilian population. Asian Pac J Cancer Prev 12: 363-368, 2011.

34. Nguansangiam S, Jesdapatarakul S, Dhanarak N and Sosrisakorn K: Accuracy of fine needle aspiration cytology of salivary gland lesions: routine diagnostic experience in Bangkok, Thailand. Asian Pac J Cancer Prev 13: 1583-1588, 2012 . 